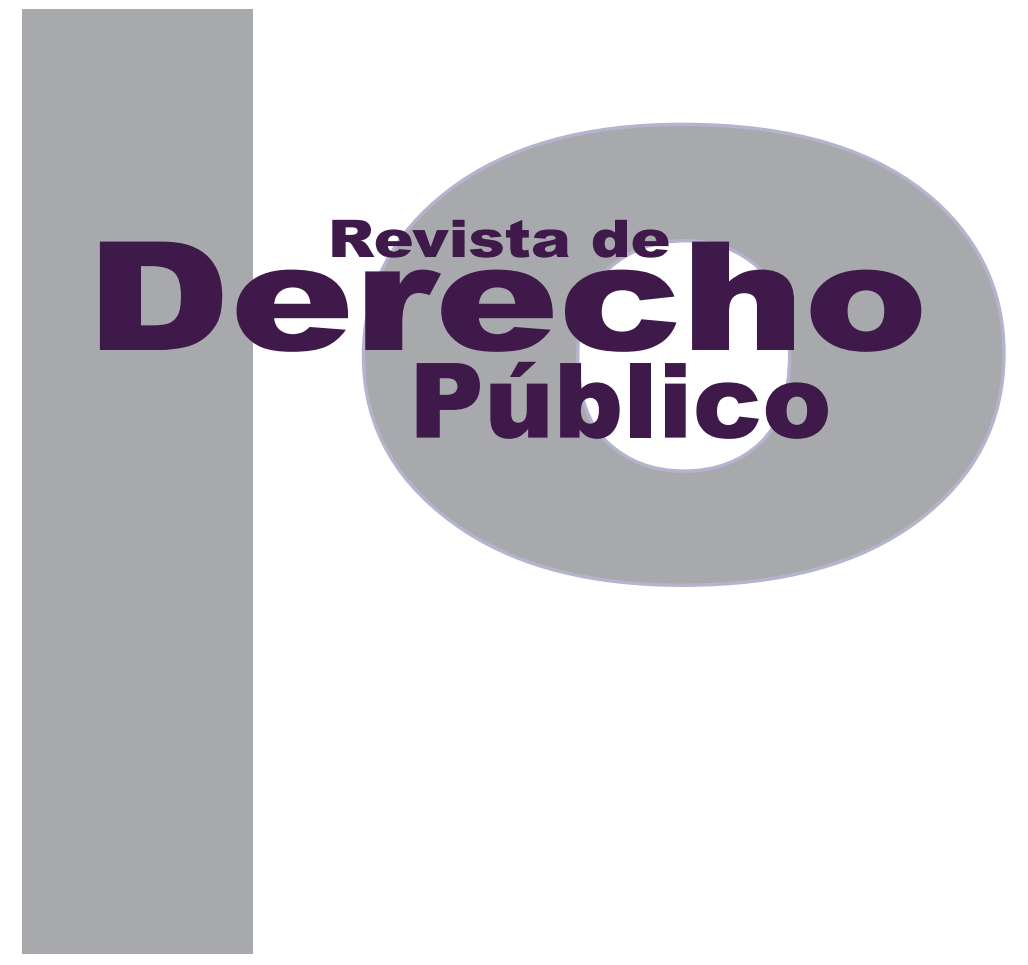

\title{
CONTRATO SOLEMNE PARA PAREJAS DEL MISMO SEXO EN COLOMBIA
}

\author{
Juan Sebastián Alejandro Perilla Granados \\ Artículo de reflexión
}

DOI: http://dx.doi.org/10.15425/redepub.35.2015.04

\author{
Universidad de los Andes \\ Facultad de Derecho \\ Rev. derecho publico No.35 \\ julio - diciembre de 2015. ISSN 1909-7778
}




\section{Contrato solemne para parejas del mismo sexo en Colombia}

\section{Resumen}

Con la sentencia C-577/11 la Corte Constitucional colombiana creó un contrato solemne análogo al matrimonio para las parejas del mismo sexo y exhortó al Congreso de la República para que lo reglamentara en un plazo de dos años. Sin embargo, el Congreso no realizó la respectiva reglamentación y, en consecuencia, por primera vez existió en el sistema jurídico colombiano un contrato solemne creado desde la doctrina constitucional sin reglamentación especial. Este artículo tiene por objetivo presentar, desde las iusteorías formalista y antiformalista, una interpretación posible para subsanar la laguna existente en el sistema jurídico, para lo cual se hace evidente el rol de la Corte Constitucional como máximo tribunal colombiano, la línea jurisprudencial relacionada y un ejercicio hermenéutico desde las iusteorías mencionadas.

Palabras clave: matrimonio, contrato solemne, parejas homosexuales, formalismo, antiformalismo, Corte Constitucional, analogía.

\section{A formal contract for same sex couples in Colombia}

\section{Abstract}

Colombian Constitutional Court Decision C-577/11 created a formal contract, which is analogous to marriage for samesex couples and urged Congress to regulate it within two years. However, Congress failed to make the respective regulation and, accordingly, a formal contract arising out of constitutional doctrine with no special regulations, was created for the first time in the Colombian legal system. This article seeks to present, using ius formalistic and anti-formalistic theories, a possible interpretation to fill this gap in the legal system by using case law from Colombian's highest court, the Constitutional Court, related case law and a hermeneutical exercise using the ius theories mentioned.

Key words: marriage, formal contract, same-sex couples, formalism, antiformalism, Constitutional Court, analogy.

\section{Contrato solene para casais do mesmo sexo na Colômbia}

\section{Resumo}

Com a sentença C-577/11 a Corte Constitucional colombiana criou um contrato solene análogo ao casamento para os casais do mesmo sexo e exortou ao Congresso da República para que o regulamentasse em um prazo de dois anos. Porém, o Congresso não realizou a respectiva regulamentação e, como consequência, por primeira vez existiu no sistema jurídico colombiano um contrato solene criado desde a doutrina constitucional sem regulamentação especial. Este artigo tem por objetivo apresentar, desde as teorias formalista e antiformalista, uma possível interpretação para corrigir a lacuna existente no sistema jurídico, para o qual se faz evidente o papel da Corte Constitucional como máximo tribunal colombiano, a linha jurisprudencial relacionada e um exercício hermenêutico desde as teorias mencionadas.

Palavras-chave: casamento, contrato solene, casais homossexuais, formalismo, antiformalismo, Corte Constitucional, analogia. 


\title{
Contrato solemne para parejas del mismo sexo en Colombia*
}

\author{
Juan Sebastián Alejandro Perilla Granados ${ }^{* *}$
}

\section{SUMARIO}

Introducción - I. LA CORTE CONSTITUCIONAL Y LA IUSTEORÍA DEL SISTEMA JURÍDICO COLOMBIANO - II. LÍNEA JURISPRUDENCIAL SOBRE FAMILIA HOMOSEXUAL Y PRECEDENTES RELEVANTES DEL CONTRATO SOLEMNE A. Sentencias C-075/2007 y C-029/2009 - III. SENTENCIA C-577/2011, CONTRATO SOLEMNE Y MATRIMONIO HOMOSEXUAL - IV. CONCLUSIONES - Referencias.

* Cómo citar este artículo: Perilla Granados, J. S. (Diciembre, 2015). Contrato solemne para parejas del mismo sexo en Colombia. Revista de Derecho Público, 35. Universidad de los Andes (Colombia).

** Abogado Cum Laude de la Universidad de los Andes, con Opción en Educación y Opción de Estudios Críticos de Género y Sexualidad en la misma Institución. Especialista en Derecho Comercial, magíster en Educación y magíster en Derecho Privado de la Universidad de los Andes. Profesor universitario del Área de Derecho Privado. Asesor del Icfes para el diseño de la prueba Saber Pro de Derecho y Competencias Ciudadanas. Se ha desempeñado como director de Docencia de la Universidad Católica de Colombia y director de Innovación Educativa de la Universidad Sergio Arboleda. Es el actual Decano de Educación de la Universidad Sergio Arboleda. Correo: js.perilla117@gmail.com 
Introducción

La Constitución Política colombiana de 1991 adscribe su sistema jurídico a una iusteoría antiformalista, según la cual el derecho es un conjunto de normas de naturaleza abierta, con vacíos o lagunas. Esa naturaleza abierta permite y exige que las normas sean complementadas por múltiples fuentes, una de las cuales es la jurisprudencia de los jueces y, en particular, de la Corte Constitucional. Para generar el complemento desde múltiples fuentes se requiere una interpretación auténtica, a manera de ejercicio hermenéutico ecléctico según cada contexto en particular.

Al aplicar lo anterior al tema de las parejas del mismo sexo y su reconocimiento como familia, se evidencia un vacío o laguna en el derecho. Tal vacío se genera porque el legislador tradicional no se ocupó del tema, presentándose un campo ambiguo respecto de su aprobación o prohibición. A falta de fuente tradicional que supere la laguna presentada, la Corte Constitucional -en calidad de juez constitucional máximo- ha generado interpretaciones auténticas que sugieren la posibilidad de que las parejas homosexuales puedan conformar familia. La interpretación auténtica de la Corte emplea un número plural de métodos de interpretación y articulación de normas desde contextos específicos.

Sobre el particular se ha de señalar que desde el año 2007 la Corte Constitucional ha consolidado una línea jurisprudencial tendiente a reconocer los derechos sociales para las parejas del mismo sexo, en particular los referentes a la posibilidad de constituir familia. Este reconocimiento ha sido generado por la Corte Constitucional en calidad de guardiana e intérprete de la Constitución Política de 1991. Sin embargo, el actual precedente contiene ambigüedades respecto a si las parejas del mismo sexo pueden o no contraer matrimonio. Esta ambigüedad es propia de un derecho de naturaleza abierta propuesto por iusteorías antiformalistas, por lo cual se requiere generar desde múltiples fuentes interpretaciones auténticas para superar la laguna mencionada.

Este documento presentará una interpretación de la línea jurisprudencial actual desde la teoría jurídica, haciendo referencia a sus sentencias hito. El análisis permitirá probar la hipótesis según la cual la Corte Constitucional reconoció que las parejas del mismo sexo pueden celebrar contratos solemnes con las reglas del matrimonio civil en Colombia. Aunque la denominación sea diferente, el contrato celebrado por las parejas del mismo sexo es un matrimonio civil en realidad.

Para probar esta afirmación se guardará la siguiente estructura argumentativa: en primer lugar se delimitará la iusteoría propia del sistema jurídico colombiano actual, a partir de lo cual se establecerá el rol prevalente de la Corte constitucional en dicho sistema. En segundo lugar, se describirán las sentencias hito de la línea jurisprudencial referente al reconocimiento de derechos sociales de las parejas del mismo sexo, para evidenciar el problema hermenéutico relacionado con el matrimonio civil. Finalmente, y a partir del análisis realizado, se concluirá 
por qué en la actualidad las parejas del mismo sexo pueden celebrar contratos solemnes que en realidad son matrimonios civiles.

\section{LA CORTE CONSTITUCIONAL Y LA IUSTEORÍA DEL SISTEMA JURÍDICO COLOMBIANO}

El ordenamiento jurídico colombiano ha estado marcado por diferentes iusteorías a lo largo del tiempo, las cuales han sido establecidas por sus Constituciones (López, 2004). Tales iusteorías conllevan en sí mismas una forma de comprender e interpretar el derecho, por lo cual han de ser entendidas como "aquellos enfoques jurídicos que están llamados a permear de manera dúctil el sistema jurídico de acuerdo con las características del contexto del cual provienen" (Perilla, 2013, pág. 4). López (2004) plantea dos iusteorías principales para explicar el ordenamiento jurídico colombiano: el formalismo y el antiformalismo. ${ }^{1}$ Estas iusteorías abarcan un conjunto de métodos de interpretación y escuelas de hermenéutica jurídica que se fueron transformando históricamente en Colombia, generando la denominada cultura jurídica (García, 2008).

Debe señalarse que todos los ordenamientos jurídicos cuentan con una cultura jurídica, la

1 Se adopta la clasificación realizada por López Medina (2004), puesto que en la academia colombiana se ha convertido en un canon de referencia sobre la explicación teórico jurídica del ordenamiento jurídico nacional. Esto se hace evidente en el hecho que la mayoría de trabajos relativos al tema iusteórico y su aplicación en Colombia se remiten a este trabajo en particular. Para fundamentar esta posición se pueden consultar a manera de ejemplo: Bonilla (2009), Cely (2012) y Betancourt-Serna (2007). cual tiende a ser dinámica y cambiante según las características propias del contexto en que se encuentre. Pese a la relevancia de la cultura jurídica, en la mayoría de ocasiones no se tiene conciencia de esta y, en consecuencia, se tiende a creer que no existe; "el que niega la existencia de teoría del derecho en una cultura jurídica, tan solo afirma que él, en realidad, no es consciente de la misma" (López, 2004, pág. 51). Sin embargo, la cultura jurídica permea de forma dúctil la relación de los operadores con las normas, determinando la concepción que se tiene del derecho, sus fuentes y el rol hermenéutico de quienes se relacionan con él.

La consolidación de la cultura jurídica colombiana se ha explicado desde el tránsito de la Constitución Nacional de 1886 a la Constitución Política de 1991. Así, la Constitución de 1886 adscribía su sistema jurídico a una iusteoría formalista, según la cual el derecho es un conjunto de normas completas y perfectas creadas por el legislador tradicional y, en consecuencia, el operador jurídico está llamado a hacer interpretaciones miméticas (Barreto, 2011; Perilla, 2013). Las interpretaciones miméticas conllevan la idea que el operador jurídico no tiene la capacidad de hacer aportaciones interesantes al proceso de consolidación del derecho, por lo cual su tarea es la de repetir de la forma más fidedigna posible el texto del legislador.

La prevalencia del legislador, propia del formalismo de la Constitución de 1886, se materializa, entre otras, en una diferenciación tradicional de los poderes del Estado (Bercholc, 2014). En esta división de poderes se ubica el legislativo 
en una posición superior y subordinante respecto del ejecutivo y el judicial. Sobre el particular, señala García (2008) que bajo el amparo de la Constitución de 1886:

La existencia de derecho y su propio ejercicio están supeditados a las leyes que los creen y reglamenten (...) por tal valor esencialmente programático de la Constitución del 86 , sus normas y principios solo podían contar con una realización efectiva en la medida en que se diera un desarrollo legislativo (pág. 301).

Se evidencia así que el legislador era entendido en ese momento histórico como la fuente por excelencia del derecho, generando que todos los demás poderes carecieran de la posibilidad creativa para hacer normas.

Una de las consecuencias de esta concepción de las fuentes del derecho es reconocer al juez como un mero receptor y reproductor exégeta de la voluntad del legislador (Bernal y Montealegre, 2004), generando la imposibilidad de un derecho vivo y cambiante de acuerdo con las necesidades y exigencias del contexto (Lasalle, 1931). Desde la perspectiva de Bercholc (2014), esta división de poderes con subordinaciones entre las diferentes ramas responde a un enfoque tradicional que debe ser superado, puesto que los poderes del Estado no están claramente delimitados en la práctica del derecho y sus funciones interactúan de forma dinámica y permanente en su creación.

Este formalismo de la cultura jurídica colombiana empezó a evidenciar una falta de coherencia entre las prescripciones meramente formales y las situaciones materiales de la sociedad (Lemaitre, 2009). Se generaron así movimientos liderados por grupos sociales diversos, dando poder desde la realidad práctica a actores políticos no convencionales, pero con la capacidad suficiente para producir cambios en la configuración y el alcance del derecho (Bercholc, 2015). Se organizaron de esta manera los estudiantes, grupos armados al margen de la ley, partidos políticos nacientes, entre otros actores, y se empezó la consolidación de una nueva Constitución (Lemaitre, 2009). Sobre el particular afirma Hurtado (2006):

La reforma constitucional de 1991 fue el resultado de un proceso particularmente democrático, en comparación con otros países de América Latina y con otros episodios de la historia nacional (...) la Constitución de 1991 fue un proceso abierto donde ningún grupo político prevaleció (Dugas, 1993, p. 45-76; Cepeda, 1993, p. viii-xx) y por esto mismo no se pudo prever con certeza el resultado de la nueva carta $(\text { p. } 97)^{2}$

Sobre el particular, Dávila (2002) afirma categóricamente que el proceso democrático de consolidación de la Constitución de 1991 se refirió a un pacto entre diversos grupos sociales, que

2 A manera de ejemplo sobre por qué la Constitución de 1991 es resultado de un proceso democrático sin precedentes próximos en Latinoamérica se puede consultar a Dugas (1993) y Cepeda (1993). Además, Hurtado (2006) ejemplifica esta afirmación así: "En efecto, a diferencia de otras reformas constitucionales de los 80 y los 90 en la región, la Asamblea Nacional Constituyente (ANC) en Colombia, no fue una simple artimaña del ejecutivo para aprobar su reelección y/o para implementar medidas de ajuste económico —como ocurrió con Menem en Argentina, Fujimori en Perú, o Chávez en Venezuela-. La reforma constitucional de 1991 tampoco fue un sello de victoria militar de un partido sobre otro, como ocurría en el siglo XIX (Valencia, 1987, p. 80-97), o un "pacto de caballeros" (Wilde, 1978) como en el caso de la reforma de 1957, donde se excluyeron terceras fuerzas distintas al bipartidismo liberal-conservador" (pág. 97). 
desde el contexto de cada uno de ellos aportaron para hacer un cambio sustancial en la concepción del derecho que conllevaba la Constitución de 1886. Así, desde una pluralidad de contextos se construyó una Constitución con un enfoque iusteórico diferente, pues se contemplaba la posibilidad de la existencia de múltiples fuentes y se empoderaba a los diferentes operadores jurídicos para hacer interpretaciones diversas del derecho (Shugart, 1999). Se dispersó de esta forma el poder del Estado, lo que en términos de Bercholc (2014) representaría un proceso innovador para la creación del derecho, categorizado como prodemocrático. ${ }^{3}$

Como consecuencia de este proceso democrático (y prodemocrático) en el que participó un conjunto heterogéneo de grupos políticos, con la entrada en vigencia de la Constitución Política colombiana de 1991 el ordenamiento jurídico cambió su enfoque iusteórico y se adscribió al antiformalismo (Bonilla, 2006; Lemaitre, 2009). Esta iusteoría entiende que el derecho tiene una naturaleza abierta, lo cual permite que sea complementado por múltiples fuentes y, consecuentemente, el operador jurídico está Ilamado a hacer interpretaciones auténticas (Perilla, 2015).

Con este cambio constitucional iusteórico, y siguiendo la propuesta de Recasens (1980), en

3 Sobre el tema de la prodemocracia, Bercholc (2014) señala: "En un Estado democrático, en su primer eslabón, la participación política de los ciudadanos requiere ser canalizada a través de partidos políticos que contengan y transmitan las demandas de la ciudadanía hacia las instituciones estatales. Sin embargo, otros modos de participación, han sido hace ya bastante tiempo reivindicados por la doctrina como prodemocráticos, a despecho de algunos lastres históricos que los suponían a contrapelo de las prácticas democráticas" (pág. 81).
Colombia se consolida con el antiformalismo lo que ha sido denominado por la doctrina como el nuevo derecho. Sobre el particular se puede tener en cuenta que:

La expresión 'nuevo derecho' se ha referido en Colombia, fundamentalmente desde la expedición de la Constitución del 91, a una serie de transplantes iusteóricos, además de los conocidos transplantes dogmáticos como leyes o códigos, y a la difusión y consolidación de una serie de argumentos de corte antiformalista e ideologías antitradicionales que hacen uso constante de lecturas transformadoras de la Teoría Transnacional del Derecho como crítica a la cultura jurídica preponderante, esencialmente relacionadas con la interpretación y aplicación del derecho (García, 2008, pág. 292).

Para determinar si se está en presencia o no de un nuevo derecho, el formalismo y el antiformalismo se pueden medir desde la teoría de la alineación iusteórica (Perilla, 2013, pág. 12), la cual se encuentra condensada en el mapa 1:4

4 El mapa encuentra así su explicación: "El ejercicio de identificación de iusteorías es valioso, toda vez que permite comprender las dinámicas que inspiran la consolidación del derecho más allá de la simple literalidad de las normas. Sin embargo, tal labor carecería de utilidad práctica si se reduce a un ejercicio abstracto del deber ser; limitarse a identificar iusteorías, transplantes y mutaciones de estas para solamente concluir cómo está estructurado el derecho no genera un impacto trascendental en las dinámicas cambiantes de cada sistema jurídico. Por esta razón se propone que una vez identificada la iusteoría de cada sistema jurídico (y sus elementos), deben evaluarse los diferentes regímenes que hacen parte de tal sistema y generar propuestas prácticas que aseguren alineación entre el enfoque jurídico y las normas existentes" (Perilla, 2013, pág. 11). 
Mapa 1. Análisis de un régimen jurídico en el espectro

iusteórico formalista y antiformalista

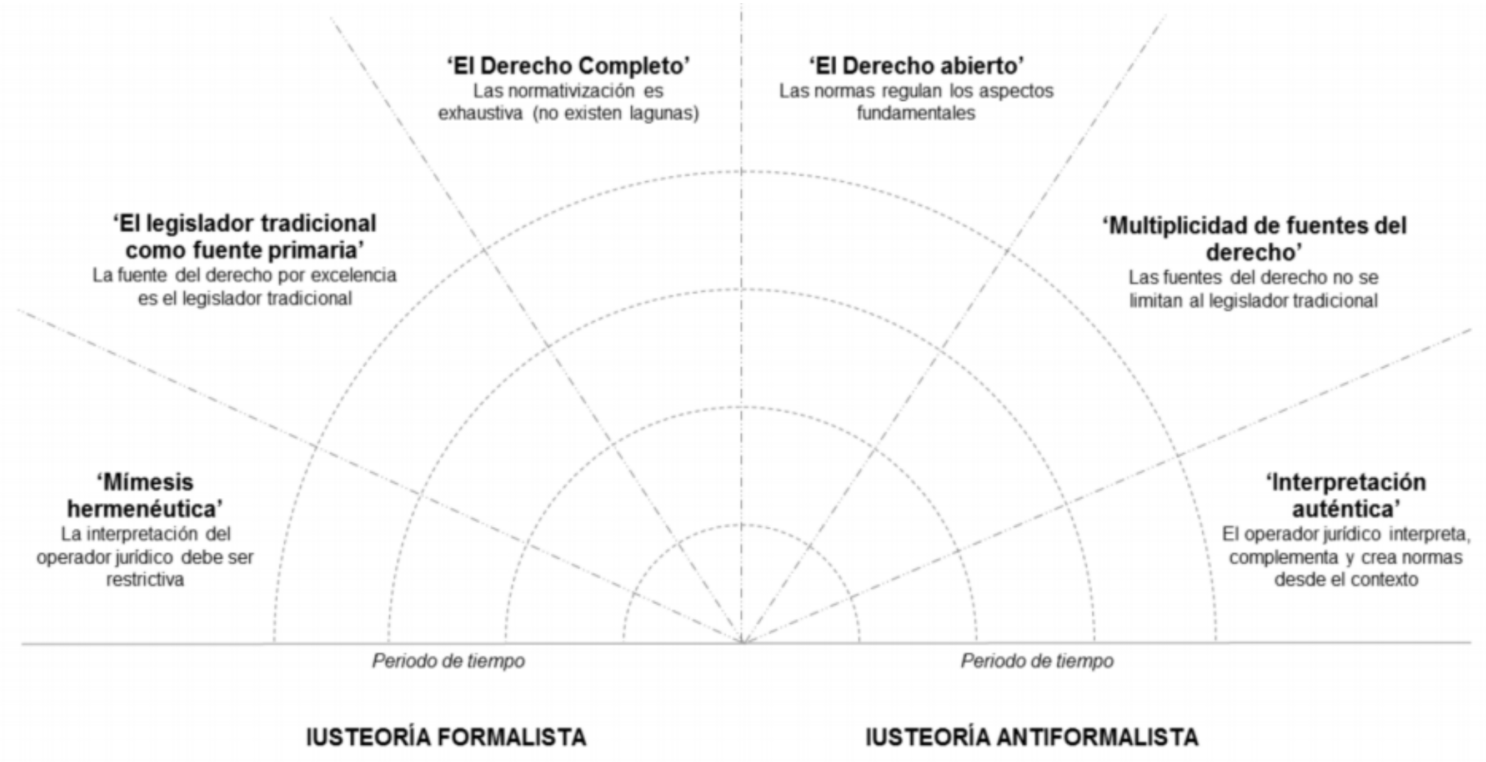

Elaboración propia fundamentada en Perilla (2013).

Como parte del cambio iusteórico del formalismo al antiformalismo en el ordenamiento jurídico, la nueva Carta Magna crea la Corte Constitucional, y el artículo 241 superior determina expresamente que a dicha corporación "se le confía la guarda de la integridad y supremacía de la Constitución". Esto implica que la Corte Constitucional es un tribunal cuyos pronunciamientos hacen parte íntegra de la Constitución Política a través de la doctrina constitucional, a saber:

La doctrina constitucional es la Constitución misma que, dada su generalidad, tiene que ser aplicada a través de los usos concretos de la misma, hechos por su intérprete institucional (...) en casos de vacío legislativo, entonces, se aplica directamente la Constitución y su interpretación autorizada (López, 2004, pág. 43).

El hecho que los pronunciamientos de la Corte Constitucional hagan parte íntegra de la Consti- tución Política de 1991 materializa de manera directa el antiformalismo, puesto que se reconoce que el derecho es de naturaleza abierta y, en consecuencia, cuenta con lagunas que han de ser llenadas por los operadores jurídicos. Desde la iusteoría antiformalista, la Corte Constitucional es aquel tribunal que por excelencia está llamado a subsanar las lagunas que se presenten en el derecho y no el legislador tradicional propio del formalismo (Álvarez, 1994).

En términos de Lasalle (1931), la Corte Constitucional a través de la permanente interpretación auténtica que realice de la Constitución asegura que esta no sea un documento de papel sin utilidad práctica, sino que se materialice de forma real y efectiva en la sociedad. Así, la Corte Constitucional tiene la tarea de asegurar que la Constitución sea un cuerpo normativo vivo que responda de forma permanente a las 
necesidades que se gestan en el conglomerado social (Arango, 1993). Se establece así que el legislador tradicional ya no es la autoridad más importante en el sistema jurídico, sino que es la Corte Constitucional quien interpreta las normas existentes e incluso puede crear otras para garantizar la vida de la Constitución (Lasalle, 1931; Olano, 2010; Rodríguez, 1999).

Ahora bien, para el formalismo, la Corte Constitucional podría tener una mera labor de interpretación mimética, materializando -entre otras- la propuesta de Dworking (1985, 2000, 2002) que permite al juez acudir a valores de cada contexto para interpretar las normas en casos particulares, sin cumplir funciones de legislador. ${ }^{5}$ Sobre el particular, Dworking (2002) -como representante del formalismo- propende por asegurar que los jueces puedan decidir dentro del marco de las normas ya existentes y sin hacer interpretaciones auténticas sino apegadas a las reglas de estas. Esto lo justifica al afirmar que:

Una comunidad debe ser gobernada por hombres y mujeres elegidos por la mayoría y responsables ante ella. Como los jueces, en su mayoría, no son electos, y como en la práctica no son responsables ante el electorado de la manera que lo son los legisladores, el que los jueces legislen parece comprometer esta proposición (Dworking, 2002, pág. 150).

5 Se sigue la propuesta de Dworking porque se ubica en un momento histórico que agrupa diferentes posiciones formalistas $y$, a pesar de intentar superarlas, se encarga de reafirmarlas. Además de las fuentes aquí señaladas, se recomienda profundizar en el debate consultando a Bonilla (1996), Pérez (2010), Rodríguez (1997) y Vargas (2013).
Sin embargo, la interpretación de la Constitución que hace la Corte Constitucional no es un razonamiento silogístico perfecto y tampoco se basa en la utilización de principios y valores unívocos de naturaleza cerrada (Cifuentes, 1997). Por el contrario, la Corte Constitucional por regla general está llamada a aplicar criterios propios de decisiones razonables, y no meramente racionales, contando con un amplio margen de decisión y actuación interpretativa (Atienza, 1989; Zuluaga y Bedoya, 2014). Se evidencia así, que la Corte Constitucional está llamada a subsanar lagunas del sistema jurídico en calidad de fuente máxima del derecho, con la aplicación de métodos hermenéuticos auténticos (López, 2004, 2006; Perilla, 2013).

Se reformula de esta forma la concepción de las fuentes del derecho, dando prevalencia a través de la Constitución Política de 1991 a otros actores que pueden crear normas desde la iusteoría antiformalista, a saber:

Esta nueva sensibilidad iusteórica e ideológica se implantó y fortaleció por la labor vanguardista y progresista de la Corte Constitucional, y por el destacado papel de algunas academias jurídicas nacionales (...) donde se empezó a publicar a principios de los noventa una importante literatura, propia o por traducciones, que importaba y adecuaba nuevos abordajes iusteóricos (García, 2008, págs. 292-293).

En atención a la calidad de juez superior del sistema jurídico colombiano que ostenta la Corte Constitucional, se describe a continuación la línea jurisprudencial que ha consolidado este tribunal respecto del derecho a la familia de las 
parejas del mismo sexo. Debe advertirse una vez más - retomando lo explicado sobre la doctrina constitucional- que las sentencias de la Corte Constitucional hacen parte íntegra de la Constitución desde una iusteoría antiformalista y, en consecuencia, los fallos jurisprudenciales que serán analizados son la Constitución misma.

\section{LÍNEA JURISPRUDENCIAL SOBRE FAMILIA HOMOSEXUAL $Y$ PRECEDENTES RELEVANTES DEL CONTRATO SOLEMNE}

El artículo 42 de la Constitución Política de 1991 determina que "la familia se constituye por vínculos naturales o jurídicos, por la decisión libre de un hombre y una mujer de contraer matrimonio o por la voluntad responsable de conformarla". Los vínculos naturales hacen referencia - de manera principal pero no exclusiva- a la filiación que es dada por el parentesco por consanguinidad (Lafont, 2013; Montoya, 2013). Por su parte, los vínculos jurídicos se dividen en dos: primero, el matrimonio que está limitado exegéticamente a las parejas heterosexuales $\mathrm{y}$, segundo, la voluntad responsable que no cuenta con sujetos determinados (Jiménez, 1998). ${ }^{6}$

Se hace evidente así la materialización del antiformalismo en la definición constitucional

6 Se evidencia de esta forma que el matrimonio entre heterosexuales no es la única fuente de la familia, sino que la expresión referente a la voluntad libre y responsable abre la posibilidad para que la familia se constituya a través de diversas formas. A diferencia del matrimonio, limitado para las parejas heterosexuales, la voluntad no hace tal referencia. Por esta razón, la Constitución desde sus inicios ha contemplado la voluntad para que los homosexuales -entre otros grupos diferentes a la familia nuclear de hombre, mujer e hijosconstituyan familia. de la familia, puesto que esta cuenta con una naturaleza abierta, es decir, declarativa y no taxativa. Cuando se hace referencia a la voluntad responsable se rompen los parámetros de normalidad tradicionalmente impuestos, y se comprende que es posible la existencia de familias con características propias diversas. ${ }^{7}$ Retomando la iusteoría propia de la Constitución de 1991, la naturaleza abierta de la definición de familia puede ser complementada por múltiples fuentes, una de las cuales es el juez en sede de constitucionalidad.

Al respecto, la Corte Constitucional ha desarrollado interpretaciones tendientes a incluir en este artículo a las parejas del mismo sexo (Hoyos, 2012). A continuación se presentarán las sentencias hito que han reconocido de manera efectiva los derechos a la familia de estas parejas, atendiendo a las reglas utilizadas en Colombia para construir líneas jurisprudenciales propuestas por López (2006). ${ }^{8}$

Siguiendo a Hoyos (2012), la línea jurisprudencial de la Corte Constitucional que ha reconocido derechos a las parejas del mismo sexo para constituir familia a través de matrimonio

La diversidad de la familia se puede materializar en un número plural de ejemplos, a saber: familias de crianza, madres cabeza de familia, familias uniparentales, núcleos familiares entre abuelos y nietos, igualdad de derechos entre los menores adoptados y los hijos naturales, entre otros.

8 Téngase en cuenta que no se analizan sentencias referentes a adopción de menores de edad por parte de parejas del mismo sexo. Esta decisión se justifica en que a pesar de que la adopción es una fuente de la familia por voluntad responsable materializada en la filiación por parentesco civil, el debate principal en torno al matrimonio no tiene una relación directa con la adopción. Se busca también desmontar aquella percepción social según la cual la aprobación del matrimonio civil genera una consecuencia inmediata sobre relaciones de filiación de menores de edad. 
y/o unión marital de hecho está conformada por las siguientes sentencias: C-075/07 (reconocimiento de la sociedad patrimonial de la Ley 54 de 1990), C-811/07 (régimen de seguridad social en salud a pareja homosexual), T-856/07 (afiliación a salud de compañeros permanentes), C-336/08 (pensión de sobrevivientes en pareja homosexual), C-798/08 (asistencia alimentaria en parejas del mismo sexo), T-1241/08 (pensión de sobrevivientes en pareja homosexual), C-029/09 (aclaración respecto a la unión marital de hecho y ampliación de cuarenta normas para parejas del mismo sexo) y C-577/11 (análisis del contrato de matrimonio, exhortación al Congreso y configuración de contrato solemne). Ahora bien, solamente se analizarán tres sentencias hito, a saber: C-075/2007 por ser la primera en reconocer el derecho a la familia de las parejas homosexuales, a través del análisis de la Ley 54 de 1990; C-029/2009 por reconocer expresamente la unión marital y aplicarla de manera sistemática a normas que la mencionan en el ordenamiento jurídico y C-577/2011, por ser la primera en reconocer un déficit de protección respecto al contrato de matrimonio.

\section{A. Sentencias C-075/2007 y C-029/2009}

La primera sentencia hito de la Corte Constitucional que conlleva un reconocimiento positivo del derecho a la familia para las parejas del mismo sexo es la C-075/2007, en la cual los demandantes buscaban que en el marco de la voluntad responsable incluida en el artículo 42, ya mencionado, se reconociera a las parejas del mismo sexo la posibilidad de constituir uniones maritales de hecho (Bonilla, 2008a). ${ }^{9}$ La Corte Constitucional se encontraba aquí frente a un caso emblemático, puesto que sería la primera sentencia en reconocer los derechos de segunda generación referentes a la familia homosexual.

En un intento político por contrarrestar el impacto mediático, la Corte decidió en esa sentencia reconocer los efectos patrimoniales de la Ley 54 de 1990, es decir, la sociedad patrimonial de hecho. Se trató de una decisión ambigua y poco clara, pues "si la Corte Constitucional colombiana lo hubiera querido, con esta sola sentencia hubiera logrado hacer una transformación global del sistema jurídico colombiano" (Bonilla, 2008b, pág. 10). Siendo así, a partir de la sentencia se presentaron confusiones en torno a su alcance, y la comunidad jurídica en general entendió que los homosexuales podían tener vínculos societarios, pero no constituir una familia (Bonilla, 2008b; Hoyos, 2012).

La ambigüedad de la Corte Constitucional solamente obedeció -en términos de Bercholc (2015) - a una estrategia política para que la decisión fuera interpretada como razonable por los diferentes grupos sociales presentes en CoIombia. Aquellos grupos sociales adheridos al

9 Según la Ley 54 de 1990, la unión marital de hecho es un negocio consensual cuyo requisito de existencia es una convivencia seria, notoria, ininterrumpida y permanente de dos personas naturales con capacidad de ejercicio (Parra, 2008). La unión marital de hecho existe desde el primer día de convivencia, pero sus efectos patrimoniales (sociedad patrimonial) nacen transcurridos dos años de esta (Daza, 2015). Quiere decir que una vez cumplida la condición suspensiva de la sociedad, seguirá la suerte del vínculo principal y también existirá desde el primer día (Quiroz, 2007). 
formalismo sentirán que la decisión fue razonable, puesto que solamente se reconocen efectos patrimoniales y no familiares (Cubides, 2011a). Por su parte, los grupos más antiformalistas reconocerán la ventaja de poder constituir vínculos jurídicos para proteger situaciones personales que carecían de protección por parte del derecho (Bonilla, 2008b).

Dos años más tarde la Corte Constitucional aclaró de manera sistemática y organizada, a través de la sentencia C-029/2009, que las parejas del mismo sexo son una familia en atención a lo descrito en la sentencia C-075/2007. Señaló igualmente que la sociedad patrimonial es el vínculo accesorio de la unión marital y, siguiendo el principio general del derecho, no puede existir un vínculo accesorio sin el principal. ${ }^{10}$ En este sentido, cuando se reconoció la sociedad patrimonial, se reconoció al mismo tiempo la unión marital de hecho en calidad de vínculo principal. El argumento de la Corte se fundamentó en que la Constitución Política no excluía a las parejas homosexuales para constituir familia a través de voluntad responsable, como sí lo hacía expresamente en el matrimonio. Por lo anterior, en la sentencia C-029/2009 decidió que una proporción casi absoluta de las expresiones referentes a unión marital de parejas heterosexuales incluidas en el sistema jurídico actual debían ser aplicadas a las parejas del mismo sexo. De esta manera, la interpretación y aplicación de más de cuarenta normas fue modificada a través de esta única sentencia.

10 Sobre las relaciones entre elementos principales y accesorios se recomienda consultar: Arévalo (2012), Arias (2008), Arias (2014), Ochoa (2014), Quiroz (2000), Ternera (2014) y Velásquez (2014).
Se debe señalar que estos casos han de ser catalogados como fáciles (Atienza, 1997), puesto que el juez aplicó la siguiente deducción: si la Constitución señala que todos los ciudadanos son iguales y la voluntad como vínculo de la familia no está limitada a los heterosexuales, entonces los homosexuales pueden constituir familia a través de su voluntad responsable. Este trabajo jurisprudencial de la Corte materializa lo señalado por Atienza (1989) sobre las decisiones racionales, pues cumple con los supuestos exigidos: en primer lugar, cumple con las reglas de la lógica deductiva, porque todas las premisas necesarias para llegar a la conclusión están en el mismo sistema jurídico (incluso implícitamente, como en el caso de los criterios constitucionales para alegar la igualdad de las parejas del mismo sexo); segundo, se fundamenta en los principios de la racionalidad práctica, en particular los de consistencia, eficiencia, coherencia, generalización y sinceridad; ${ }^{11}$ tercero, utiliza como premisas algunas fuentes del derecho vinculantes, en particular la misma Constitución y la ley tradicionalmente aplicada a parejas del mismo sexo; y cuarto, los elementos decisivos de la fundamentación están previstos específicamente en el sistema jurídico, incluyendo valores, principios y criterios políticos.

De esta forma, la Corte Constitucional interpretó la Constitución aclarando que las parejas del mismo sexo pueden constituir familia a través del vínculo jurídico referente a la voluntad libre y responsable. Sin embargo, aún no existía una

\footnotetext{
11 Aunque Atienza (1989) compila estos principios, su propuesta encuentra la fundamentación principal en las siguientes obras: Aarnio (1987), Alexy (1978) y Peczenik (1984).
} 
respuesta por parte de este tribunal respecto a si los homosexuales pueden o no celebrar un matrimonio. Fue hasta el año 2011, con la sentencia C-577, cuando la Corte Constitucional se refirió al tema en particular.

\section{SENTENCIA C-577/2011, CONTRATO SOLEMNE Y MATRIMONIO HOMOSEXUAL}

A diferencia de las sentencias proferidas respecto a las parejas del mismo sexo hasta ese momento, en la sentencia C-577/11 la Corte Constitucional se enfrentó a un caso difícil que requirió de una decisión razonable (Atienza, 1989; Cianciardo, 2004). La Corte Constitucional analizó la constitucionalidad del artículo 113 del Código Civil aplicable al matrimonio, el cual limita tal institución jurídica a las parejas heterosexuales y lo define como un contrato solemne. Al respecto, la Corte, en primer lugar, reconoció un desequilibrio que atentaba contra la igualdad de las parejas del mismo sexo, porque aunque homosexuales y heterosexuales podían constituir familia por la voluntad responsable, solamente los heterosexuales podían contraer matrimonio. Dice textualmente la sentencia:

Actualmente la pareja heterosexual cuenta con dos formas de dar lugar a una familia, lo que les permite a sus miembros decidir autónomamente y ejercer su derecho al libre desarrollo de la personalidad, en tanto que la pareja homosexual carece de un instrumento que, cuando se trata de constituir una familia, les permita a sus integrantes tener la misma posibilidad de optar que asiste a las parejas heterosexuales (CConst., C-577/11, G. Mendoza).
Esta conclusión se visualiza en el mapa 2.

Mapa 2. Desequilibrio para constituir familia a través de vínculos jurídicos

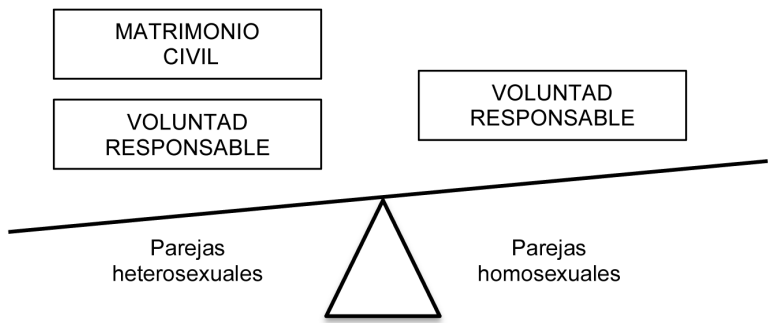

Elaboración propia fundamentada en Corte Constitucional, sentencia C-577/11.

La Corte Constitucional considera este desequilibrio un déficit de protección, porque aunque el Estado tiene la responsabilidad de proteger en condiciones de igualdad a todos sus miembros, el sistema jurídico en conjunto limita el matrimonio civil a las parejas heterosexuales y excluye de forma expresa a los homosexuales. La Corte, en su calidad de intérprete de la Constitución señala:

No se puede desconocer que en esta cuestión se encuentra profundamente involucrada la voluntad, puesto que la familia homosexual surge de la "voluntad responsable" de conformarla y no se ajusta a la Constitución que esa voluntad esté recortada, no sirva para escoger entre varias alternativas o se vea indefectiblemente condenada a encaminarse por los senderos de la unión de hecho cuando de formar familia se trate, o quede sujeta a lo que la Corte vaya concediendo, siempre que tenga la oportunidad de producir una equiparación en un campo específico (C-577/11).

Por esta razón, el máximo juez constitucional colombiano reconoce que el derecho mismo 
está limitando los derechos de los homosexuales para constituir familia y no le es dable legitimar tales desequilibrios, sino que tiene el deber de superarlos en su calidad de guardiana e intérprete de la norma superior.

El Tribunal Constitucional se enfrenta entonces a una encrucijada jurídica que se resume en los supuestos de los casos difíciles propuestos por Atienza (1991, 1997): primero, no existe una respuesta exacta y correcta en el sistema jurídico actual, porque la propia Constitución Política de 1991 señala expresamente que el vínculo matrimonial es solo para heterosexuales y no es función de la Corte cambiar el texto de la Carta (solamente interpretarlo); segundo, las formulaciones normativas que se alegan por los demandantes son ambiguas y los conceptos poseen una textura abierta (principios de pluralidad, diversidad y equidad, así como el derecho fundamental a la igualdad, libertad, dignidad, entre otros); tercero, el derecho se muestra entonces como incompleto, porque es evidente el déficit de protección pero no la forma como el mismo sistema jurídico puede resolverlo de manera exacta; cuarto, en la comunidad jurídica no hay consenso acerca de si los homosexuales pueden o no contraer matrimonio; quinto, la decisión requiere de argumentos no deductivos, por lo cual solamente se puede decidir sopesando las disposiciones jurídicas en conflicto; sexto, la estructura del razonamiento de la Corte se debe fundamentar en principios; y séptimo, la solución de la Corte exige juicios no estrictamente jurídicos. ${ }^{12}$

12 Estos principios son extraídos de la obra de Atienza (1997), quien a su vez se inspira en las obras de Barak (1987), Dowrkin (1986), Kennedy (1986), MacCormick (1978), Marmor (1991) y Navarro (1993).
Frente a este caso difícil, la primera decisión que toma la Corte Constitucional ante el déficit de protección identificado en la C-577/11 consiste en declarar la exequibilidad de la expresión hombre y mujer que estaba siendo demandada, porque lo dispuesto por el Código Civil cumple en estricto sentido lo contenido en el artículo 42 de la Constitución. ${ }^{13}$ Sin embargo, el Tribunal Constitucional implementa una institución jurídica relativamente nueva que rompe con la idea tradicional de la división de poderes: las exhortaciones. La Corte exhorta al Congreso de la República a que legisle en un plazo perentorio (junio 20 de 2013) y cree una institución análoga al matrimonio que pueda ser aplicada a parejas del mismo sexo. ${ }^{14}$

Esta exhortación realizada por la Corte Constitucional materializa el antiformalismo, según el cual el legislador tradicional no es la fuente del derecho por excelencia, y se ubica en una posición superior a este, al punto de poder determinar de forma expresa cuáles son los temas sobre los cuales se debe legislar y el sentido que deben tener las normas jurídicas. Esto se justifica en la literalidad del resuelve del Tribunal Superior, a saber:

13 Tanto el artículo 113 del Código Civil como el artículo 42 de la Constitución Política de 1991 señalan que el matrimonio civil es un contrato solemne que debe ser celebrado por un hombre y una mujer. Por esta razón no era posible declarar una inexequibilidad de la norma de rango legal.

14 Con esta decisión, la Corte Constitucional está respetando los preceptos constitucionales que determinan que el Congreso es el encargado, por excelencia, de crear normas de rango legal: si el déficit de protección se estaba presentando a nivel legal, era indispensable que se resolviera por igual forma. Al mismo tiempo, la Corte Constitucional asume su rol superior frente al Congreso y le da una orden de rango constitucional. 
EXHORTAR al Congreso de la República para que antes del 20 de junio de 2013 legisle, de manera sistemática y organizada, sobre los derechos de las parejas del mismo sexo con la finalidad de eliminar el déficit de protección que, según los términos de esta sentencia, afecta a las mencionadas parejas (CConst., C-577/11, G. Mendoza).

La Corte Constitucional, asumiendo que el Congreso cumplirá con la exhortación, determina que una vez vencido el plazo (junio 21 de 2013) las parejas del mismo sexo podrán acudir ante autoridad competente para solemnizar su vínculo contractual. Sin embargo, señala expresamente en el quinto resuelve: "Si el 20 de junio de 2013 el Congreso de la República no ha expedido la legislación correspondiente, las parejas del mismo sexo podrán acudir ante notario o juez competente a formalizar y solemnizar su vínculo contractual" (CConst., C-577/11, G. Mendoza).

Es así como la Corte Constitucional no pudo llegar a una decisión racional sino a una razonable, porque los criterios y los elementos decisivos de la fundamentación no están previstos explícitamente en el sistema jurídico; "solo está justificado acudir a criterios de razonabilidad si se muestra la insuficiencia de los criterios de racionalidad estricta, y sólo en la medida en que éstos resulten insuficientes" (Atienza, 1989, pág. 96). La razonabilidad de la decisión se materializa entonces en el alto grado de discrecionalidad que tuvo la máxima autoridad judicial colombiana, pues luego de reconocer un déficit de protección y la imposibilidad de subsanarlo con las normas existentes, se formula por pri- mera vez la conclusión de ordenar al Congreso legislar sobre una materia específica (Cubides, 2011b). Además, la tesis de la razonabilidad toma mayor relevancia por el hecho que la Corte exige que el Congreso sea quien llegue a acuerdos sociales para reglamentar la institución análoga al matrimonio para homosexuales:

La decisión a tomar en cada caso sería aquella que pueda verse como aceptable por una comunidad de seres o por un ser que la represente 0 , si hubiera varias decisiones que pudieran serlo en principio, la que pudiera lograr una mayor aceptabilidad, un mayor consenso (Atienza, 1989, pág. 104).

Pese a la solución razonable de la Corte, el Congreso -como órgano que podía asegurar un mayor consenso- no cumplió con la exhortación realizada en la sentencia C-577/11; aunque se presentaron proyectos de ley relacionados, no se surtió el debate exigido para su aprobación. La falta de actividad legislativa Ilevaría a configurar, en términos de los Estudios Críticos del Derecho representados por Posner (1988), un caso imposible. ${ }^{15}$ Las razones de esta afirmación radican en que la sentencia C-577/11 determinó, sin ningún tipo de condición, que una vez vencido el plazo (junio 20 de 2013) las parejas homosexuales podían acudir a solemnizar un vínculo contractual análogo al matrimonio. Esto implica que por medio de la doctrina constitucional se creó -y por tal razón existe en la Constitución- un contrato solemne análogo al

15 Se acoge el concepto de caso imposible y no de caso trágico propuesto por Atienza (1991), porque en esta situación no se exige la vulneración de un elemento esencial de un valor considerado como fundamental desde el punto de vista jurídico o moral. 
matrimonio para parejas del mismo sexo, pero sin reglamentación directa. Es una dicotomía compleja, puesto que la Constitución contiene una nueva institución jurídica que se puede solemnizar, pero no existe norma reglamentaria específica para esta.

Para resolver el caso imposible se requiere entonces vincular elementos jurídicos, morales, políticos, entre otros, para materializar los principios propios del Estado social, democrático y constitucional de derecho de la Constitución Política de 1991;

La posición puede reflejar una visión social que puede ser articulada y defendida aun cuando no pueda probarse que es correcta o falsa. Pocas proposiciones éticas -casi ninguna de las que la gente está interesada en debatir- puede probarse que sea correcta o equivocada y sin embargo el discurso no es infructuoso; y en los casos indeterminados, el discurso jurídico es una forma de discurso ético o político (Posner, 1988, pág. 362).

La vinculación de los distintos elementos para resolver el caso se materializará en la interpretación que se haga de la situación, de cara a lo dispuesto por el sistema jurídico (Perilla, 2013).

En desarrollo de la interpretación exigida, y retomando las iusteorías imperantes en Colombia, en la situación descrita tanto el formalismo como el antiformalismo defenderían la conclusión según la cual las parejas del mismo sexo pueden celebrar un contrato solemne exactamente igual al matrimonio civil en el país. Se debe recordar que desde el formalismo se entiende al derecho como completo, pues en caso de existir un vacío eventual este debe ser llenado por lo dispuesto por el legislador tradicional. En este caso se presenta un vacío de reglamentación sobre el contrato solemne para parejas del mismo sexo, por lo cual la respuesta la deberán dar las normas ya existentes y que han sido creadas por el mismo legislador. La única norma creada por el legislador tradicional, y que es analogizable a un contrato solemne, es la del matrimonio civil, por lo cual en una interpretación mimética deberían aplicarse las mismas reglas de los heterosexuales a los homosexuales sobre la materia. El contrato solemne de las parejas del mismo sexo que existe a nivel constitucional, requerirá desde el formalismo la aplicación de las normas legales que puedan ser objeto de analogía, es decir, las del matrimonio civil, existentes actualmente para heterosexuales. Aunque la denominación del vínculo para las parejas del mismo sexo sería la de contrato solemne, siguiendo un principio de realidad el contenido es idéntico.

Por su parte, el antiformalismo acepta que el derecho tiene lagunas que deben ser resueltas por múltiples fuentes a través de interpretaciones miméticas. En este caso existe la laguna referente a la reglamentación del contrato solemne para parejas del mismo sexo, la cual debe ser llenada por los diferentes operadores jurídicos. La interpretación auténtica exigida es, entonces, aquella que se aleja de interpretaciones exegéticas, dándole un sentido amplio al contrato de matrimonio civil planteado para las parejas heterosexuales. Este sentido amplio sería una interpretación auténtica, que llevaría a aceptar que por analogía de las normas las parejas del 
mismo sexo podrían celebrar su vínculo contractual siguiendo las reglas del único contrato solemne existente y así superar el déficit de protección: el matrimonio civil heterosexual.

Teniendo en cuenta que las normas de rango legal deben ser creadas por el legislador, y que este no cumplió en este caso con su deber constitucional, la solución más razonable sería aplicar una analogía de las normas legales para reglamentar el contrato solemne existente en la misma Constitución Política de 1991 por parte de la doctrina constitucional. Esta propuesta toma relevancia al analizar el texto constitucional, creado a través del Tribunal Constitucional Superior, a saber:

Doctrinariamente se ha destacado que el recurso a la analogía es de gran utilidad cuando el juez constitucional enfrenta cuestiones en las que normalmente hay un amplio desacuerdo en la sociedad plural y se encuentran involucradas disputas de profunda índole moral, pues limitándose a extender a otras personas o grupos el ámbito de los cobijados por alguna medida específica, da una respuesta basada en lo que el legislador ha dispuesto en relación con un caso asimilable a la situación concreta no prevista en el respectivo precepto, manteniéndose dentro del ámbito de sus competencias, con total respeto por la facultad configurativa del legislador, cuyas competencias no resultan invadidas por la sentencia constitucional (CConst., C-577/11, G. Mendoza).

Se evidencia así que el déficit de protección reconocido por la Corte Constitucional, en principio, era un caso difícil y a falta de reglamentación del Congreso se configuró un caso impo- sible que requería vincular elementos interpretativos adicionales, particularmente la analogía. Se trata, pues, de un caso sin precedentes en Colombia, puesto que: primero, se crea un contrato por vía constitucional que carece de reglamentación legal directa; segundo, para solucionar la falta de reglamentación, convergen en la analogía el formalismo y el antiformalismo; y tercero, a pesar de haber reconocido que el contrato para los homosexuales debía ser diferente, la inactividad legislativa generó a través de un hecho histórico que las parejas del mismo sexo puedan celebrar contratos solemnes con el único vínculo jurídico de la familia existente: el matrimonio civil. Es dable entonces proponer que dadas las características contextuales e históricas colombianas, las parejas del mismo sexo llegaron a celebrar vínculos contractuales que, por analogía, son matrimonios civiles.

\section{CONCLUSIONES}

Con la Constitución Política de 1991, Colombia se adscribió a un Estado social, democrático y constitucional de derecho, cuya iusteoría imperante es el antiformalismo. Esta iusteoría reconoce que el derecho es abierto, por lo cual cuenta con lagunas que deben ser llenadas por múltiples fuentes a través de la aplicación de interpretaciones auténticas. Para asegurar que estos principios establecidos por la Constitución tengan una naturaleza dúctil, a la Corte Constitucional se le confió la guarda de la integridad y supremacía de la Constitución. Esta función implica que lo que dice el Tribunal Constitucional es la Constitución misma, pues sus pronuncia- 
mientos hacen parte íntegra de la Carta Magna a través de la teoría de la doctrina constitucional. En desarrollo de sus funciones de guardiana de la Constitución, la Corte Constitucional desde el año 2007 inició un reconocimiento de los derechos sociales a la familia para las parejas del mismo sexo. Desde el artículo 42 de la Constitución Política, la familia tiene vínculos naturales y jurídicos; entre los jurídicos se encuentran el matrimonio para parejas heterosexuales y la voluntad responsable, vínculo que no está limitado a ningún tipo de sujetos. En el marco de esta voluntad responsable, la Corte Constitucional reconoció la existencia de uniones maritales para parejas del mismo sexo, lo cual se hace evidente en la línea jurisprudencial reiterada y materializando una serie de casos fáciles.

Sin embargo, a través de la sentencia C-577/11 la Corte Constitucional se enfrentó a un caso difícil, al reconocer que sobre el tema del matrimonio existía un déficit de protección para las parejas del mismo sexo frente a las heterosexuales. El caso fue resuelto mediante criterios de razonabilidad, exhortando al Congreso para que llegara a un consenso social y creara una institución jurídica análoga. Asumiendo que el Congreso cumpliría con la exhortación, la Corte creó en la sentencia C-577/11 un vínculo contractual análogo al matrimonio para heterosexuales, el cual podría ser solemnizado por parejas del mismo sexo una vez vencido el plazo establecido por el Congreso. No obstante, el Congreso no legisló y el contrato solemne existe a nivel constitucional pero sin reglamentación directa en la ley, configurándose así un caso imposible que requiere de la interpretación de elementos jurídicos, políticos, morales, etc.

Para desarrollar esta interpretación del caso imposible, se acude tanto al formalismo como al antiformalismo, evidenciando que desde las dos iusteorías las parejas del mismo sexo deberían solemnizar su contrato con las mismas reglas del matrimonio civil. Así, el ejercicio hermenéutico permite evidenciar que como materialización de los principios propios del sistema jurídico actual, en particular el principio de realidad, el vínculo contractual para las parejas del mismo sexo y para las parejas heterosexuales solamente se podría diferenciar en su denominación: el primero se llama contrato solemne y el segundo matrimonio, porque en esencia y por analogía es la misma institución jurídica.

\section{Referencias}

1. Álvarez Jiménez, A. (1994). Dos nuevas acciones para la defensa de la Constitución. Revista de Derecho Público, 5, 23-48.

2. Arango Rivadeneira, R. (1993). Jurisdicción e interpretación constitucional. Revista de Derecho Público, 4, 31-38.

3. Arévalo Guerrero, I. H. (2012). Bienes: constitucionalización del derecho civil. Bogotá: Universidad Externado de Colombia.

4. Arias García, F. (2008). Bienes civiles y mercantiles. Bogotá: Grupo Editorial Ibáñez. 
5. Aarnio, A. (1987). The rational as reasonable: A treatise on legal justification. Boston: Reidel.

6. Alexy, R. (1978). Theorie der jurstischen Argumentation. Die Theorie des rationalen Diskurses als Theorie der juristischen Begründung. Francfort am Main: Suhrkamp Verlag.

7. Arias García, C. (2014). Bienes civiles y mercantiles. Bogotá: Grupo Editorial Ibáñez.

8. Atienza, M. (1989). Sobre lo razonable en el derecho. Revista Española de Derecho Constitucional, 9, 27, 93-110.

9. Atienza, M. (1991). Las razones del Derecho: teorías de la argumentación jurídica. Madrid: Centro de Estudios Constitucionales.

10. Atienza, M. (1997). Los límites de la interpretación constitucional. De nuevo sobre los casos trágicos. Anuario de la Facultad de Derecho de la Universidad Autónoma de Madrid, 1, 245-265.

11. Barak, A. (1987). Judicial Discretion. New Haven: Yale University Press.

12. Barreto Rozo, A. (2011). Venturas y desventuras de la regeneración. Apuntes de historia jurídica sobre el proyecto político de 1886 y sus transformaciones y rupturas en el siglo XX. Bogotá: Ediciones Uniandes.

13. Bercholc, J. (2014). Temas de teoría del Estado. Buenos Aires: La Ley.
14. Bercholc, J. (2015). Opinión pública y democracia. Buenos Aires: Lajouane.

15. Bernal, J. y Montealegre, E. (2004). De la estricta lógica formal a la lógica de lo razonable. En El proceso penal: fundamentos constitucionales del nuevo sistema acusatorio (Quinta ed.). Bogotá: Universidad Externado de Colombia.

16. Betancourt-Serna, F. (2007). La recepción del Derecho Romano en Colombia. Salamanca: Universidad de Sevilla.

17. Bonilla, D. E. (1996). Ronald Dworkin - La comunidad liberal. Bogotá: Siglo del Hombre Editores.

18. Bonilla, D. E. (2006). La Constitución multicultural. Bogotá: Siglo del Hombre Editores.

19. Bonilla, D. E. (2008a). El derecho de interés público, igualdad y parejas del mismo sexo en Colombia. Journal of Emergent Socio-legal Studies, 2, 23-40.

20. Bonilla, D. E. (2008b). Igualdad, orientación sexual y derecho de interés público: la historia de la sentencia C-075/2007. En Parejas del mismo sexo: el camino hacia la igualdad. Bogotá: Universidad de los Andes/Colombia Diversa.

21. Bonilla, D. E. (2009). Teoría del derecho y transplantes jurídicos. Bogotá: Siglo del Hombre Editores. 
22. Cianciardo, J. (2004). El principio de razonabilidad: del debido proceso al moderno principio de proporcionalidad. Buenos Aires: Ábaco.

23. Cely Ortiz, L. A. (2012). El carácter especulativo de la iusteoría periférica. Revista Prolegómenos. Derechos y Valores, 17, 34, 3341.

24. Cepeda, M. J. (1993). La Constituyente por dentro. Bogotá: Imprenta Nacional de Colombia.

25. Cifuentes Muñoz, E. (1997). La igualdad en la jurisprudencia de la Corte Constitucional. Revista de Derecho Público, 7.

26. Corte Constitucional de Colombia. Sentencia C-075 de 2007 (M. P.: Rodrigo Escobar Gil; febrero 7 de 2007).

27. Corte Constitucional de Colombia. Sentencia C-811 de 2007 (M. P.: Marco Gerardo Monroy Cabra; octubre 3 de 2007).

28. Corte Constitucional de Colombia. Sentencia C-856 de 2007 (M. P.: Humberto Antonio Sierra Porto; octubre 12 de 2007).

29. Corte Constitucional de Colombia. Sentencia C-336 de 2008 (M. P.: Clara Inés Vargas Hernández; abril 16 de 2008).

30. Corte Constitucional de Colombia. Sentencia C-798 de 2008 (M. P.: Jaime Córdoba Triviño; agosto 20 de 2008).
31. Corte Constitucional de Colombia. Sentencia T-1241 de 2008 (M. P.: Clara Inés Vargas Hernández; diciembre 11 de 2008).

32. Corte Constitucional de Colombia. Sentencia C-029 de 2009 (M. P.: Rodrigo Escobar Gil; enero 28 de 2009).

33. Corte Constitucional de Colombia. Sentencia C-577 de 2011 (M. P.: Gabriel Eduardo Mendoza Martelo; julio 26 de 2011).

34. Cubides, J. A. (2011a). Disertaciones sobre las parejas del mismo sexo a través del rol ejercido por la Corte Constitucional colombiana en el reconocimiento de sus derechos. Anuario de Derecho, 28, 13-36.

35. Cubides, J. A. (2011b). El rol de la jurisprudencia de la Corte Constitucional en los derechos de las parejas del mismo sexo. Jurídicas, 9, 61-69.

36. Daza Coronado, S. M. (2015). Derecho de familia. Bogotá: Editorial Universidad Católica de Colombia.

37. Dávila, A. (2002). Democracia pactada: el Frente Nacional y el proceso constituyente del 91. Bogotá: Alfaomega/Ceso-Uniandes, Departamento de Ciencia Política/Instituto Francés de Estudios Andinos.

38. Dugas, J. (1993). La Constitución de 1991: un pacto político viable? Bogotá: Universidad de los Andes. 
39. Dworkin, R. (1985). A Matter of Principle. Cambridge: Harvard University Press.

40. Dworkin, R. (1986). Law's Empire. Londres: Fontana Press.

41. Dworkin, R. (2000). ¿Entran en conflicto la libertad y la igualdad? En P. Barker (Comp.) Vivir como iguales. Barcelona: Paidós.

42. Dworkin, R. (2002). Los derechos en serio. Barcelona: Ariel.

43. García, L. (2008). El “nuevo” derecho en CoIombia: ¿Entelequia innecesaria o novedad pertinente? Revista de Derecho, 29, 289330.

44. Hoyos Rojas, L. M. (2012). El método neoconstitucional de la dignidad en el derecho privado: una aproximación a la igualdad de género en el ámbito de las relaciones familiares homoparentales. Revista de Derecho Privado, 47.

45. Hurtado, M. (2006). Proceso de reforma constitucional y resolución de conflictos en Colombia: el frente nacional de 1957 y la Constituyente de 1991. Revista de Estudios Sociales, 27, 97-104.

46. Jiménez Valencia, F. (1998). La protección integral a la familia desde una perspectiva constitucional. Revista de Derecho Privado, 22, 209-246.

47. Kennedy, D. (1986). Freedom and Constraint in Adjudication. Journal of Legal Education, 36.
48. Lafont Pianetta, P. (2013). Derecho de familia. Bogotá: Librería Ediciones del Profesional.

49. Lasalle, F. (1931). ¿Qué es una Constitución? Madrid: Editorial Cenit S. A.

50. Lemaitre Ripoll, J. (2009). El derecho como conjuro: fetichismo legal, violencia y movimientos sociales. Bogotá: Siglo del Hombre Editores/Universidad de los Andes.

51. López Medina, D. E. (2004). Teoría impura del derecho: la transformación de la cultura jurídica latinoamericana. Bogotá: Legis.

52. López Medina, D. E. (2006). El derecho de los jueces: obligatoriedad del precedente constitucional, análisis de sentencias y líneas jurisprudenciales y teoría del derecho judicial. Bogotá: Ediciones Uniandes/Legis Editores.

53. MacCormick, N. (1978). Legal Reasoning and Legal Theory. Oxford: Clarendon Press.

54. Marmor, A. (1991). Interpretation and Legal Theory. Oxford: Clarendon Press.

55. Montoya Osorio, M. E. (2013). Derecho de familia. Medellín: Librería Jurídica Dikaia.

56. Navarro, P. E. (1993). Sistema jurídico, casos difíciles y conocimiento del Derecho. Doxa, 14.

57. Ochoa Carvajal, R. H. (2014). Bienes. Bogotá: Temis. 
58. Olano García, H. A. (2010). Fuentes del Derecho: ley, costumbre, jurisprudencia, doctrina y principios generales del derecho. Bogotá: Doctrina y Ley.

59. Parra Quijano, J. (2008). Derecho de familia. Bogotá: Temis.

60. Peczenik, A. (1984). A model of legal reasoning. Rechrstheorie, 10.

61. Pérez Jaraba, M. D. (2010). Principios y reglas: examen del debate entre R. Dworkin y H. L. A. Hart. Revista de Estudios Jurídicos, 10, $1-24$.

62. Perilla Granados, J. S. (2013). Alineación iusteórica desde las licencias creative commons. Revista de Derecho Privado, 50.

63. Perilla Granados, J. S. (2015). Alineación iusteórica de las fuentes del derecho comercial. Revista de Derecho Privado, 53.

64. Posner, R. A. (1988). The jurisprudence of Skepticism. Michigan Law Revue, 86.

65. Quiroz Monsalvo, A. W. (2000). Manual de bienes. Bogotá: Ediciones Doctrina y Ley.

66. Quiroz Monsalvo, A. W. (2007). Manual civil familia. Bogotá: Ediciones Doctrina y Ley.
67. Recasens, L. (1980). Nueva filosofía de la interpretación del derecho. México D. F.: Porrúa.

68. Rodríguez, C. (1997). La decisión judicial: el debate Hart-Dworkin. Bogotá: Siglo del Hombre Editores.

69. Rodríguez, C. (1999). Una crítica contra los dogmas de la coherencia del derecho y la neutralidad de los jueces: los estudios críticos del derecho y la teoría de la decisión judicial. En D. Kennedy, Libertad y restricción en la decisión judicial. Bogotá: Siglo de Hombre Editores.

70. Shugart, M. (1999). Constitucional Change in Colombia. Comparative Political Studies, 32(3), 313-341.

71. Ternera Barrios, F. (2014). Bienes. Bogotá: Universidad del Rosario.

72. Vargas Duque, G. E. (2013). Casos difíciles y dilemas en el derecho. Revista de Filosofía Conceptos. 3, 107-115.

73. Velásquez Jaramillo, L. G. (2014). Bienes. Bogotá: Temis.

74. Zuluaga Jaramillo, A. F. y Bedoya Atehortúa, J. (Diciembre, 2014). Análisis crítico de las directivas de interpretación constitucional creadas por la dogmática jurídica. Revista de Derecho Público, 33. 